\title{
Comparative analysis of the tear protein profile in herpes simplex virus type 1 epithelial keratitis
}

Hua Yang ${ }^{1,2,3,4,5}$, Xiaozhao Yang ${ }^{1,2,3,45^{*}}$, Yani Wang ${ }^{1,2,3,4,5}$, Xuan Zheng ${ }^{1,2,3,4,5}$, Yi Zhang ${ }^{1,2,3,4,5}$ and Yan Shao ${ }^{1,2,3,4,5}$

\begin{abstract}
Background: Herpes simplex virus type 1 (HSV-1) keratitis is a major cause of corneal blindness in the world, and an in-depth understanding of its pathogenesis may help improve existing diagnosis and treatment. The purpose of this study is to compare and analysis the total tear protein profile of HSV-1 epithelial keratitis patients, and to quantify the potential candidate biomarkers of HSV-1 epithelial keratitis.

Methods: We investigated the proteome in tear fluid from three HSV-1 epithelial keratitis patients and three healthy control subjects using nano-scale liquid chromatography-tandem mass spectrometry (nLC-MS/MS) analysis. Functional annotation of differentially expressed proteins was done with the Gene Ontology (GO) analysis. ELISA was done to quantify the potential candidate biomarkers in 26 clinical cases.

Results: Tear fluid from three HSV-1 epithelial keratitis patients and three healthy control subjects contained a total of 1275 proteins and 326 proteins were unique to tear fluid of HSV-1 epithelial keratitis patients. Bioinformatics analysis revealed that tear proteins from HSV-1 epithelial keratitis patients may be involved in metabolic processes, antigen presentation, inflammatory response, and in the TNF-mediated and T cell receptor pathways. Furthermore, IL1A, IL12B, DEFB4A, and CAMP, which are associated with the inflammatory response and inhibition of viral infection, were significantly more abundant in the HSV-1 epithelial keratitis patients than in the healthy control subjects.
\end{abstract}

Conclusions: This study reports the proteomic profile of tears in HSV-1 epithelial keratitis for the first time and identifies a number of unique differentially expressed proteins.

Keywords: HSV-1 epithelial keratitis, Tears, Proteome, Mass spectrometry, Bioinformation, ELISA

\section{Background}

Herpes simplex virus type 1 (HSV-1) is the most important pathogen causing ocular diseases in the world [1]. More than 40,000 new cases caused by HSV-1 infection each year, which range from mild corneal epithelial inflammation to severe chronic corneal ulcerations [2, 3]. Despite the diagnosis and treatment of eye disease have

\footnotetext{
*Correspondence: xiaozhao_sx@126.com

'Department of Ophthalmology, Xi'an No.1 Hospital, Xi'an 710002, Shaanxi Province, China

${ }^{2}$ Shaanxi Institute of Ophthalmology, Xi'an 710002, Shaanxi Province, China Full list of author information is available at the end of the article
}

enormous progress, HSV-1 keratitis still remains a leading cause of visual impairment and eventually blindness, and there is currently no effective vaccine available [4, 5]. Corneal disease due to HSV-1 commonly presents as epithelial keratitis which, though usually self-limiting, may persist or progress without treatment [2]. The use of antiviral drugs can effectively alleviate the HSV-1 epithelial keratitis process; however, their toxicity is often a problem, and efficacy can be limited due to the development of drug-resistant mutants [6]. The increasing prevalence of acyclovir- and multidrug-resistant HSV- 
strains is the main reason for treatment failure of inflammatory corneal HSV-infections [7]. Therefore, studying the pathogenesis of HSV-1 epithelial keratitis is essential for ensuring its early diagnosis and developing novel, well-tolerated treatment options for patients.

Tears are a complex biological mixture known to have electrolytes, lipids, enzymes, metabolites, small organic molecules, and proteins [8]. Their main function is to provide lubrication and nutrition to the cornea, and become the first line of defense against pathogens [8]. Proteins are the most abundant components in human tears, accounting about $95 \%$ of their dry weight. Therefore, changes in tear protein composition can directly reflect the physiological and pathological state of the eye tissue [9]. High-throughput proteomics technology provides a comprehensive analysis of the tear proteome and can be used as a screening method for ocular diseases such as dry eye disease [10, 11], bacterial keratitis [12], fungal keratitis [13, 14], diabetic retinopathy $[15,16]$, and thyroid-associated eye disease [17]; systemic diseases like breast cancer [18, 19] and neurological disorders [20]; and for discovering potential new therapeutic targets for these clinical situations. Therefore, studying the characterization of proteomic changes associated with HSV-1 epithelial keratitis will help to elucidate its pathogenesis, and further identify the therapeutic targets of disease.

In this study, we aimed to investigate changes in the tear proteome in HSV-1 epithelial keratitis patients. Using nano-scale liquid chromatography-tandem mass spectrometry (nLC-MS/MS), we generated tear proteome data of three HSV-1 epithelial keratitis patients, performed Gene Ontology (GO) analysis, and analyzed the levels of four specific proteins (IL1A, IL12B, DEFB4A, and CAMP) identified in tears of 26 HSV-1 epithelial keratitis patients. In summary, we identified novel proteins and pathways associated with the molecular mechanisms of HSV-1 epithelial keratitis. This study is the first report of tear proteome data from HSV-1 epithelial keratitis patients.

\section{Methods}

\section{Patients and tear collection}

This study conformed to the ethical guidelines of Declaration of Helsinki, and was performed according to the institutional ethics committee of the Xi'an No.1 Hospital. Twenty-six HSV-1 epithelial keratitis patients who first visit the clinic (including 14 males and 12 females, with a mean age of $35.60 \pm 14.78$ years) were recruited from our hospital. Twenty-six healthy control subjects (including 13 males and 13 females, with a mean age of $32.52 \pm 15.43$ years) were recruited from the community, and they had no prior ocular complaints, no history of eye medication and wearing contact lenses, and were not on any systemic medication. There was no significant difference in gender and age between the two groups $(P>0.05)$. All patients and healthy control subjects were examined by slit-lamp biomicroscopy. In addition, corneal swabs or tears were taken aseptically and HSV-1 was identified as the causative virus by real-time PCR analysis and rapid culture [21]. After informed consent, reflex tear samples $(100 \mu$ l per sample) were collected from the inferior temporal tear meniscus using calibrated $10-\mu$ l glass microcapillary tubes (Blaubrand intraMark, Wertheim, Germany). After collection, tear samples were centrifuged at $10,000 \mathrm{~g}$ for $10 \mathrm{~min}$ to remove cellular debris, and stored at $-80^{\circ} \mathrm{C}$.

\section{Reduction, alkylation and digestion}

To digest the tear proteins, $10 \mu \mathrm{g}$ samples were treated with denaturing reagent RapiGest SF according to the instructions (Waters, Manchester, UK). Then, the samples were reduced with $10 \mathrm{mM}$ dithiothreitol (Sigma-Aldrich) at $37^{\circ} \mathrm{C}$ for $30 \mathrm{~min}$, alkylated with $25 \mathrm{mM}$ iodoacetamide (Sigma-Aldrich) at $25^{\circ} \mathrm{C}$ for $15 \mathrm{~min}$ in the dark, and digested with $0.2 \mu \mathrm{g}$ trypsin (Promega) at $37^{\circ} \mathrm{C}$ for $12 \mathrm{~h}$. Finally, the digestion reaction was stopped by addition of $1 \mu \mathrm{L} 1 \%$ formic acid (SigmaAldrich).

\section{nLC-MS/MS analysis}

Tear samples from 3 HSV-1 epithelial keratitis patients and 3 healthy control subjects were analyzed using a nanoflow high pressure liquid chromatography system interfaced to an LTQ-Orbitrap XL mass spectrometer (Thermo Fisher Scientific, Germany). Briefly, $1 \mu \mathrm{g}$ sample was loaded onto a $180 \mu \mathrm{m} \times 20 \mathrm{~mm}$ (ID) C18 column precolumn $(5 \mu \mathrm{m}, 200 \AA$, Waters Corporation) and separated on a commercial $75 \mu \mathrm{m} \times 150 \mathrm{~mm} \mathrm{C18}$ column ( $5 \mu \mathrm{m}, 100 \AA$ A, Nikkyo Technology). The analytical separation was run for $85 \mathrm{~min}$, details as follows: starting from 5 to $35 \%$ of solvent B for $55 \mathrm{~min}$, from 35 to $80 \%$ of solvent B for $10 \mathrm{~min}$, holding at $80 \%$ of solvent B for $2 \mathrm{~min}$, and equilibrating the column at $5 \%$ of $\mathrm{B}$ for $18 \mathrm{~min}$ (solvent B: $0.1 \%$ formic acid in acetonitrile). Key parameter settings for the LTQ Orbitrap XL mass spectrometer were as follows the manufacturer's specifications. The resulting spectra were recorded for each run and searched using Mascot version 2.2.03, and parameters were as follows: one missed cleavage, the fixed modification was carbamidomethylation of cysteines, the variable modification was oxidation of methionine, peptide mass tolerance was $10 \mathrm{ppm}$, fragment mass tolerance was 0.6 $\mathrm{Da}$, and false discovery rate was less than $1 \%$.

\section{Bioinformatics analysis}

A list of the proteins' Gene IDs was submitted to DAVI D 6.8 for GO enrichment analysis (http://david.abcc. 
ncifcrf.gov/home.jsp). Each cluster is given a "Fold enrichment" score based on the Fisher Exact Statistics, and $P$ values $<0.05$ were considered as significant. The unique protein spectra of tears of HSV-1 epithelial keratitis patients were subjected to hierarchical clustering with Cluster 3.0 software (http://bonsai.hgc.jp/ mdehoon/software/cluster/software.htm) and visualized with the TreeView software (http://sourceforge.net/projects/ jtreeview/files/).

\section{Enzyme-linked immunosorbent assay (ELISA)}

Tears samples collected from 26 HSV-1 epithelial keratitis patients and 26 healthy control subjects (including samples in MS experiment) were analyzed by ELISA using the Human IL-1 alpha/IL-1F1 and IL-12 p70 Quantikine ELISA Kits (R\&D Systems, Minneapolis, MN, USA), and Human DEFB4A and CAMP ELISA Kits (MyBioSource, San Diego, CA, USA). Absorbance was measured at $450 \mathrm{~nm}$ using a microplate reader.

\section{Statistical analysis}

Data are expressed as the mean \pm standard error of the mean. Sample comparisons were performed using the
Student's t-test for independent samples. Statistical analysis was conducted with SPSS version 16.0. (SPSS Inc., Chicago, IL, USA). $P$-values $<0.05$ were considered to indicate a statistically significant difference.

\section{Results}

\section{Proteomes of tears from HSV-1 epithelial keratitis patients}

We investigated the protein composition of tears from HSV-1 epithelial keratitis patients $(n=3)$ and healthy control subjects $(\mathrm{n}=3)$ according to the schematic workflow shown in Fig. 1a. In total, 807 and 950 proteins were identified in the HSV-1 epithelial keratitis patients (S1 Table) and healthy control subjects (S2 Table), respectively. Keratins have been excluded from our data, because they are well-known as common laboratory contaminants in proteomic analyses. Among the identified proteins in HSV-1 epithelial keratitis patients and healthy control subjects, only 481 were common to both groups, and 326 proteins were found to be unique to HSV-1 epithelial keratitis patients (Fig. 1b, and Table S3). As expected, highly abundant proteins such as lactotransferrin, lipocalin 1, lipocalin 2, albumin, lysozyme,

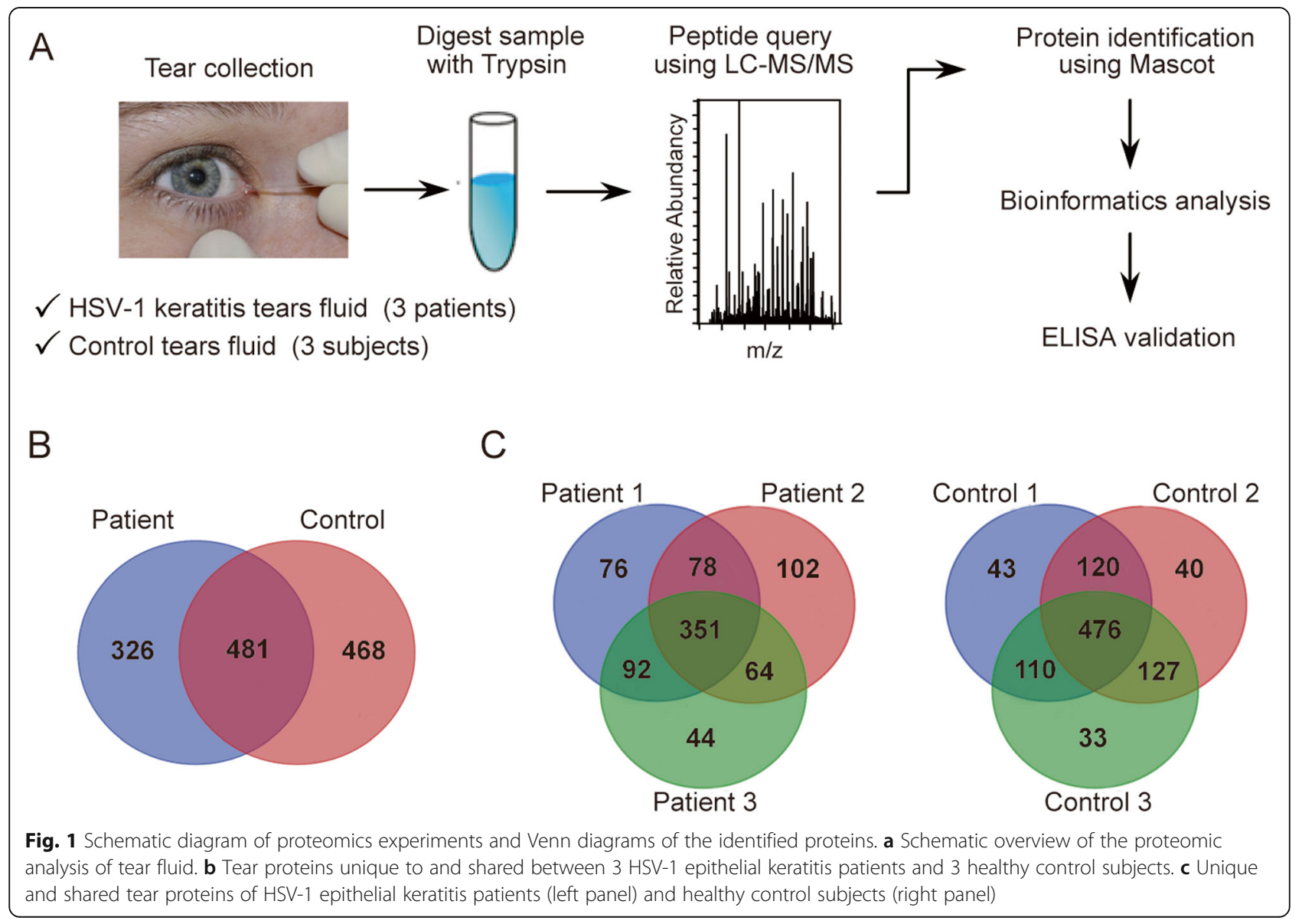


complement C3, and immunoglobulin heavy constant alpha 1 were present in tears of individuals from both groups. Most of these proteins are involved in inflammatory and antimicrobial processes, and play an important role in maintaining a clean ocular environment [22]. In the three HSV-1 epithelial keratitis patients, 597, 595, and 551 proteins were identified, respectively, while $351(43.5 \%)$ proteins were identified in all three patients (Fig. 1c). In the three healthy control subjects, 749,763 , and 746 proteins were identified, respectively, while $476(50.2 \%)$ proteins were identified in all three subjects (Fig. 1c).

\section{Functional analysis of unique proteins in tears of HSV-1 epithelial keratitis patients}

Based the DAVID enrichment analysis tool, the 326 proteins unique to HSV-1 epithelial keratitis patients were classified according to their biological processes, molecular functions and cellular components (Fig. 2). The top categories for biological processes were metabolic process, antigen presentation, inflammatory response, and TNF-mediated and $\mathrm{T}$ cell receptor pathways. This was in line with previous virus- and cell-based studies showing that HSV-1 infection induces the innate immune response, and upregulates inflammatory factors for inhibiting viral infection [23]. An unexpectedly large number of proteins were involved in cell-cell adhesion (such as CD81), and translation (such as EIF4E). This may indicate that HSV-1 interacts with corneal epithelial cells during infection, and may support the idea of adhesion, transcription, and translation of viruses [24, 25]. In addition, some proteins were assigned to the categories apoptosis, the Wnt signaling pathway, and protein polyubiquitination. We suggested that these proteins may be involved in events involving the corneal epithelial cell damage after viral infection [26]. The assignment of molecular functions revealed that HSV-1 epithelial keratitis tear proteins, preferentially bind to proteins associated with translation initiation factor activity. The other large ontology group of the tear's interactome was enzyme activity, which was mainly linked to hydrolase, oxidoreductase, and protease activity. Enrichment of these enzymes may be associated with corneal cell damage or inhibition of viral infection [27, 28]. Proteins were also categorized according to cellular components. We found that although a large number of proteins were assigned to the categories extracellular matrix and extracellular exosome system, proteins were highly enriched for the proteasome complex and cytosol. This suggests that tear protein activity in HSV-1 infections is a dynamic process, involving the communication between multiple organelles.

\section{Cluster analysis of the 326 tear proteins unique to HSV-1 epithelial keratitis patients}

To further investigate the proteins that may distinguish between HSV-1 epithelial keratitis patients and healthy controls, we analyzed the protein expression profiles of the 326 unique proteins of HSV-1 epithelial keratitis patients. We then ran a hierarchical cluster analysis of

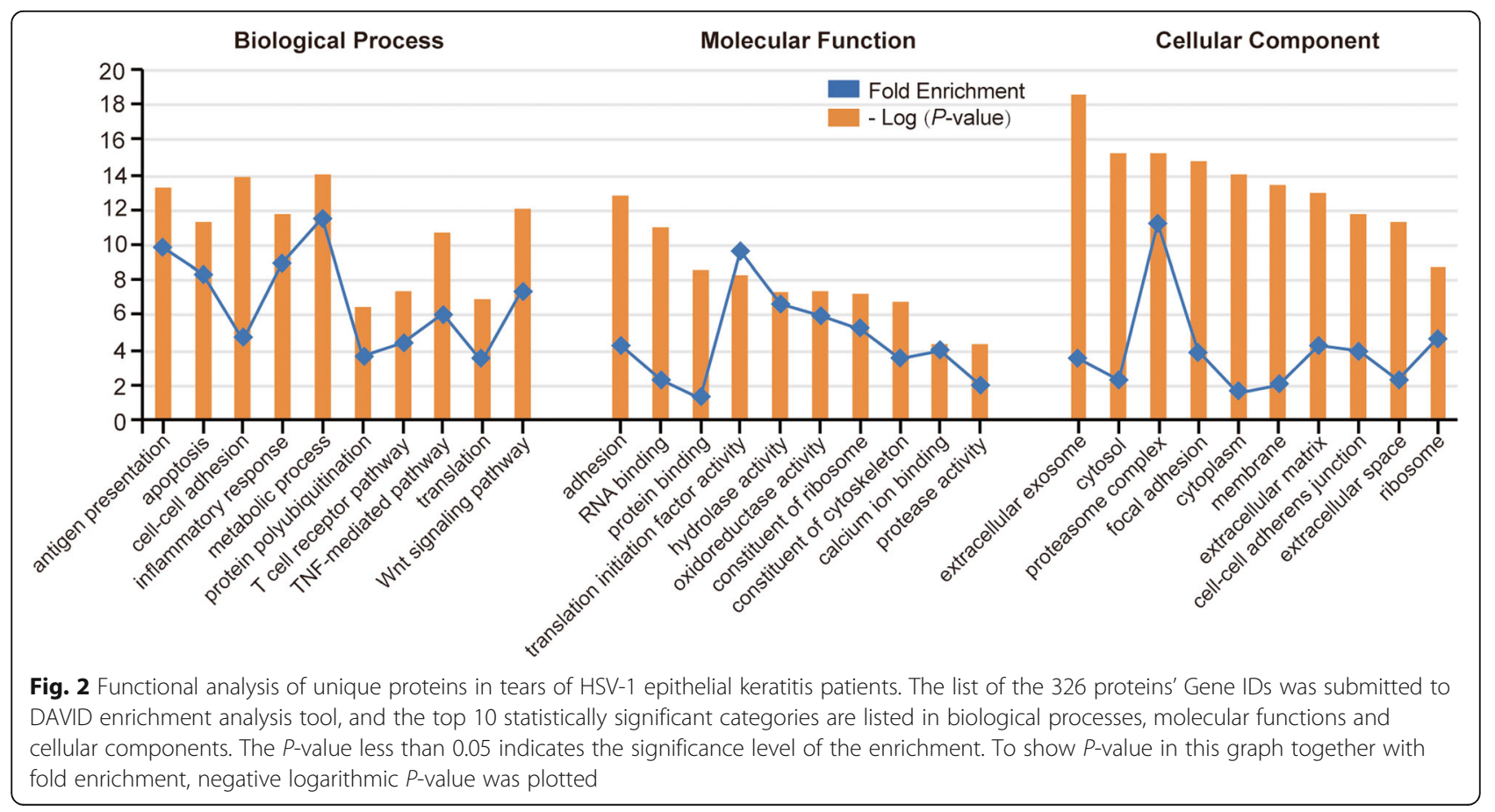


these proteins based on the number of protein spectra and cluster data were assembled to provide a heat map (Fig. 3a). Each row represents an individual protein signal and each column an individual sample. The dendrogram above the heat map shows the similarity in protein expression profiles of the samples. By comparing the differences in the tear proteomes of the three HSV-1 epithelial keratitis patients, it is clear that the tear proteome comprises proteins unique to each patient and proteins common to the three patients. Surprisingly, although several proteins including IL6, S100A8, and VEGFA were only detected in one or two patients, previous studies reported their involvement in HSV-1 epithelial keratitis [29-31]. Proteins common to all three patients included factors considered to be involved in inhibition of viral infection (such as C1QC, CAMP, DEFB4A, and S100A6), proteins associated with the inflammatory response (IL1A and IL12B) and cell damage (CASP10, EGF, HSBP1, and DRG2), and proteins with an unknown function in keratitis (PTTG1IP, CALR, CAPS, COPB1, and RAB7A) (Fig. 3b). To select appropriate proteins for ELISA analysis, we analyzed the abundance of these proteins for the three HSV-1 epithelial keratitis patients (Fig. 3c).

\section{Quantification analysis by ELISA}

To test whether these protein candidates would be detectable in clinical samples, we selected four proteins (IL1A, IL12B, DEFB4A, and CAMP) for ELISA analysis based on the following criteria: abundance, repeatability, and association with viral infection. Compared with their concentrations in 26 healthy control subjects, concentrations of IL1A, IL12B, DEFB4A, and CAMP were significantly higher in $26 \mathrm{HSV}-1$ epithelial keratitis patients. These results show that our mass spectrometry data was accurate and reliable. While the mean concentrations of IL1A, IL12B, DEFB4A, and CAMP in healthy control subjects were $(6.10 \pm 0.68 \mathrm{pg} / \mathrm{ml}), \quad(10.78 \pm 1.45 \mathrm{pg} / \mathrm{ml})$, $(21.24 \pm 3.50 \mathrm{pg} / \mathrm{ml})$ and $(3.82 \pm 0.57 \mathrm{pg} / \mathrm{ml})$ respectively, mean concentrations of IL1A, IL12B, DEFB4A, and CAMP in HSV-1 epithelial keratitis patients were $(12.26 \pm 1.78 \mathrm{pg} / \mathrm{ml})(P<0.01$, Fig. $4 \mathrm{a}), \quad(32.28 \pm 4.81 \mathrm{pg} /$
A

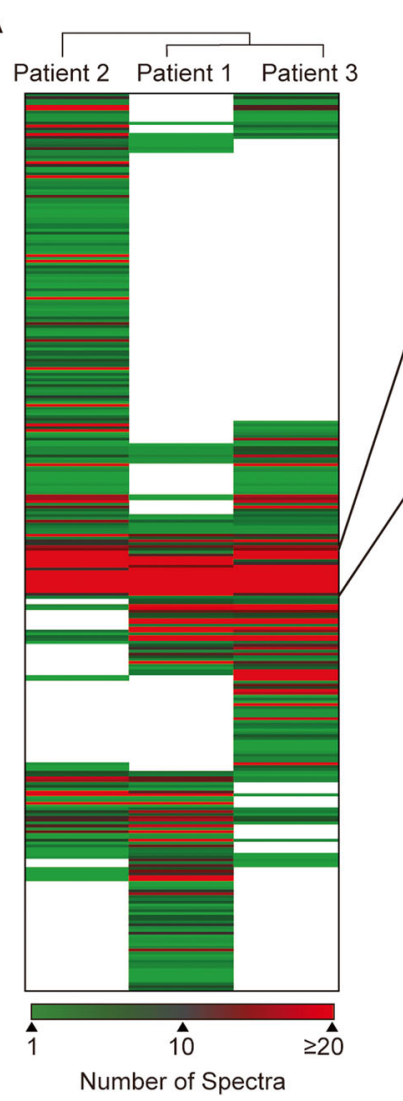

B

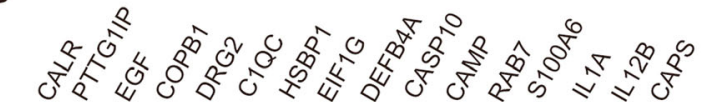

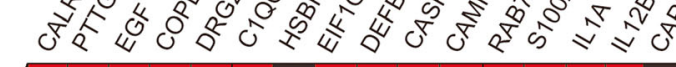

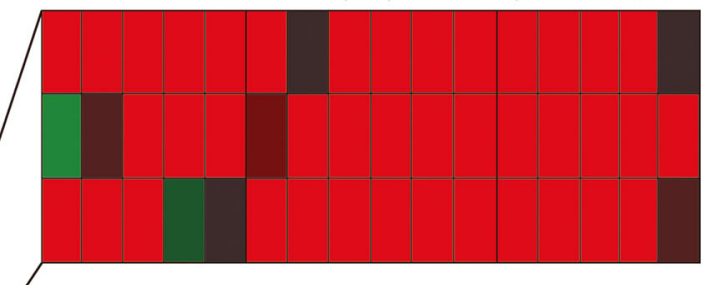

C

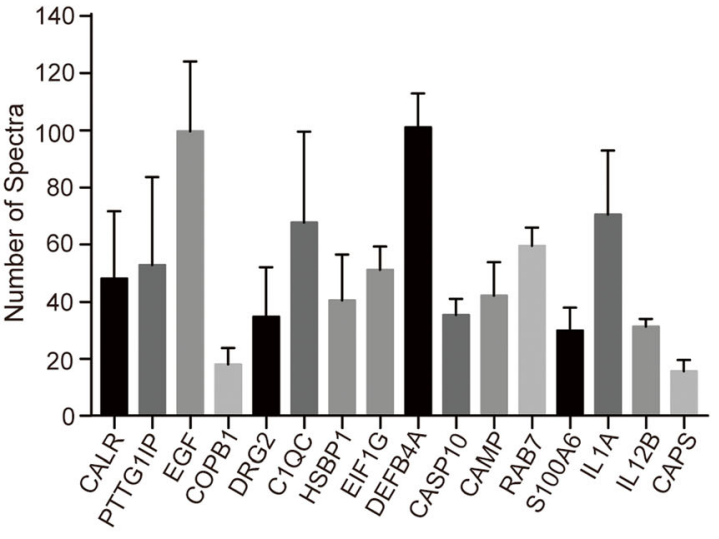

Fig. 3 Cluster analysis of the 326 unique tear proteins to the three HSV-1 epithelial keratitis patients. a Hierarchical two-dimensional clustering of the proteins based on spectral counting. Each row represents an individual protein and each column an individual patient. b Shown are highly abundant proteins present in the tears of all three patients. c Spectral counting analysis of the highly abundant proteins in three HSV-1 epithelial keratitis patients 

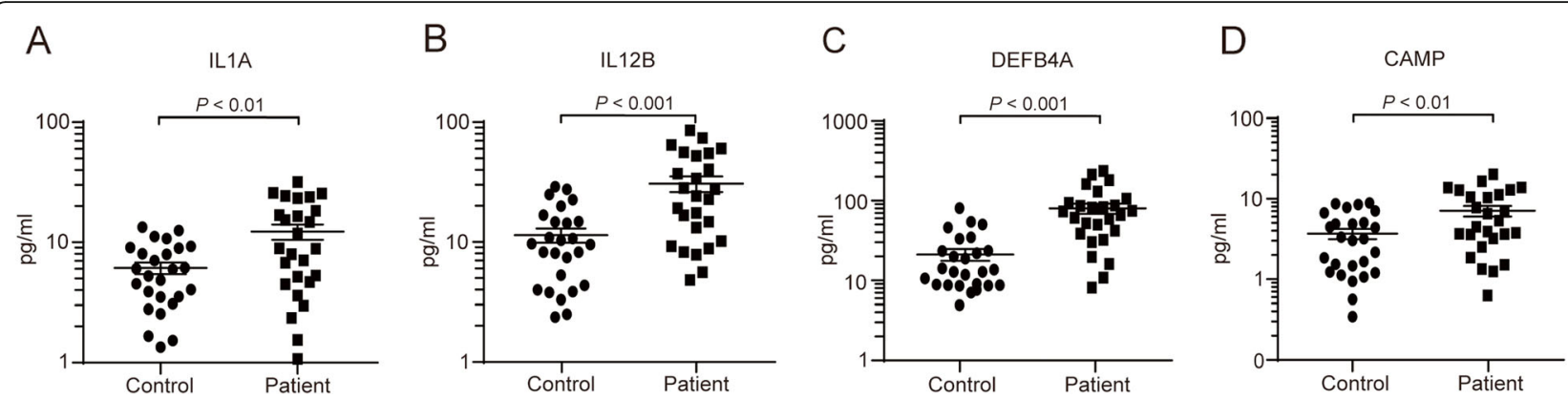

Fig. 4 The concentration of IL1A (a), IL12B (b), DEFB4A (c), and CAMP (d) in 26 HSV-1 epithelial keratitis patients and 26 healthy control subjects were measured using ELISA. Data represents mean \pm SEM of three independent experiments and were analyzed using an unpaired t-test

ml) $(P<0.001$, Fig. 4b), $(77.71 \pm 11.13 \mathrm{pg} / \mathrm{ml})(P<0.001$, Fig. 4c), and $(7.34 \pm 1.11 \mathrm{pg} / \mathrm{ml}) \quad(P<0.05$, Fig. $4 \mathrm{~d})$, respectively.

\section{Discussion}

Protein profiles of tears from HSV-1 infected individuals may show increased levels of proinflammatory cytokines, alterations in signaling molecules and hormone levels, presence of autoantibodies, factors involved in apoptosis, and many other changes [32]. Therefore, alterations in tear protein profiles are indicative of the processes underlying HSV-1 epithelial keratitis, and identification of marker proteins can provide information on the disease severity, as well as on the underlying pathology.

In this study, we identified 1275 proteins in the tear from three HSV-1 epithelial keratitis patients and three healthy control subjects using nLC-MS/MS. Zhou et al has reported a high-confidence human tear proteome reference set which contains 1543 proteins (from four healthy subiects) [33]. By comparing our tear proteome data with their tear proteome data reference set, we found that 1026 proteins (80.5\% of total 1275 proteins) were common, while 952 proteins were identified in healthy control subjects, and 596 proteins were identified in HSV-1 epithelial keratitis patients. By comparing the differences in the tear proteomes between HSV-1 epithelial keratitis patients and healthy control subjects, 326 proteins were found to be unique to HSV-1 epithelial keratitis patients. This result suggest that infection of the cornea with HSV-1 leads to significant change in the protein composition of tears, which may be due to the abnormal secretion of lacrimal glands and corneal cell damage [9]. GO enrichment analysis suggest that these unique proteins do not only participate in the host immune response, but also in cell damage and stress response. Through cluster analysis, we obtained several proteins with highly abundance and repetition rate in the tear from three HSV-1 epithelial keratitis patients (Fig. 3b-c). Most of these proteins are related to inhibition of viral infection, inflammatory response and cell damage, and may serve as a target for studying the pathogenesis and treatment of HSV-1 epithelial keratitis. It has to be noted that although some proteins (IL-6, S100A8 and VEGFA) were present in low abundance or in one or two patients only, they also play an important role in the process of HSV-1 keratitis [29-31].

HSV-1 epithelial keratitis is thought to be caused by the virus replicating in and destroying epithelial cells [2]. The lesions start as punctuate vesicular eruptions in the corneal epithelium, progressing to a stellate erosion, but quickly coalesce into dendritic shaped lesions [34]. In order to suppress the infection and replication of the virus, the expression of various inflammatory factors and antiviral proteins were increased in corneal epithelial cells [35]. Our mass spectrometry data showed the spectrum of several inflammatory factors were increased in tears of HSV-1 epithelial keratitis patients, such as IL1A and IL12B (Fig. 3 and S1 Table). ELISA also confirmed that IL1A and IL12B were significantly elevated in patients with HSV-1 epithelial keratitis (Fig. 4). The current research shows that IL1A and IL-12B are important proinflammatory cytokines in HSV-1 epithelial keratitis and are not only produced by activated macrophages and lymphocytes, but also by corneal epithelium and keratocytes [36]. When corneal epithelial cells are damaged by virus invasion, IL1 and IL12B are released as early warning signal [37]. Local release of IL1A and/ or IL12B triggers a series of events including an increase in the activity of inflammatory mediators such as prostaglandins, leukotrienes, and nitric oxide [38,39]. At the same time, upregulated inflammatory mediators promote the accumulation of neutrophils, macrophages, Langerhans cells, and lymphocytes [38, 39]. In addition to increased expression of inflammatory factors, related antiviral proteins were also increased in tears of HSV-1 epithelial keratitis patients. Human DEFB4A (also named $\beta$-defensin-2), an inducible, anti-microbial peptide with a molecular mass of 4-6 kD, acts as an endogenous antibiotic in the defense against microbial infections [40]. DEFB4A is only found occasionally in 
healthy ocular surface tissue, but it is found more frequently in infected/inflamed ocular surface tissue [41]. CAMP (also named LL-37), the sole know member of the cathelicidin family of peptide expressed in humans, is a multifunctional host defense molecule essential for normal immune responses to infection and tissue injury [42]. Studies have shown that corneal and conjunctival epithelia express CAMP as part of mucosal innate immunity to protect against bacterial and viral ocular infections [43]. Notably, in a rabbit model of corneal injury, epithelial expression of CAMP was upregulated and levels of CAMP in the tears correlated with wound closure [44]. Such observations have led to the suggestion that DEFB4A and CAMP may be important for ocular surface wound healing.

This study is the first report of tear proteome data from HSV-1 epithelial keratitis, which may deepen our understanding of molecular mechanisms behind HSV-1 epithelial keratitis. However, there are some possible limitations in this study, including the small sample size, the lack of clinical data related to disease severity. In addition, due to the limited volume of tear fluid, the collection technique will affect the protein profile of the tear sample. Future, we will focus on the correlation between the unique proteins of HSV-1 epithelial keratitis and the severity and/or prognosis of the disease. This requires a larger sample size and follow-up of patients to assess the clinical significance of these markers.

\section{Conclusions}

The present study provides an overview of the tear protein profile changes in HSV-1 epithelial keratitis patients through a proteomic approach, and identified 326 unique proteins which may have a bearing on pathogenesis and disease progression. This unique tear protein list may be used as a reference list for tear biomarker search of HSV-1 epithelial keratitis.

\section{Supplementary information}

Supplementary information accompanies this paper at https://doi.org/10. 1186/s12886-020-01626-3.

Additional file 1: Table S1. Tear proteome of HSV-1 epithelial keratitis patients.

Additional file 2: Table S2. Tear proteome of healthy control subjects. Additional file 3: Table S3. The 326 unique proteins of HSV-1 epithelial keratitis patients.

\section{Abbreviations}

HSV-1: Herpes simplex virus type 1; nLC-MS/MS: Nano-scale liquid chromatography-tandem mass spectrometry; GO: Gene Ontology; CD81: CD81 molecule; EIF4E: Eukaryotic translation initiation factor 4E; C1QC: Complement C1q C chain; CAMP: Cathelicidin antimicrobial peptide; DEFB4A: Defensin beta 4A; S100A6: S100 calcium binding protein A6; IL1A: Interleukin 1 alpha; IL12B: Interleukin 12B; CASP10: Caspase 10; EGF: Epidermal growth factor; HSBP1: Heat shock factor binding protein 1; DRG2: Developmentally regulated GTP binding protein 2; PTTG1IP: Pituitary tumor-transforming 1 interacting protein; CALR: Calreticulin; CAPS: Calcyphosine; COPB1: Coatomer protein complex subunit beta 1; RAB7A: RAB7A, member RAS oncogene family

\section{Acknowledgements}

Not applicable.

Authors' contributions

$H Y$ and $X Z Y$ designed the research and design of this study and drafted the manuscript. $H Y, X Z Y, Y W$ and $X Z$ conducted the experiments. $H Y, Y Z$ and $Y S$ analyzed the data. All authors discussed the results and commented on the manuscript. All authors read and approved the final manuscript.

\section{Funding}

This work was supported by the Xi'an Science and Technology Project [2017116SF/YX010(5)]. The funders had no role in the study design, data collection, analysis or writing of the manuscript.

\section{Availability of data and materials}

The datasets used and/or analysed during the current study are available from the corresponding author on reasonable request.

\section{Ethics approval and consent to participate}

The experimental protocol was established, according to the ethical guidelines of the Helsinki Declaration and was approved by the institutional ethics committee of the of Xi'an No.1 Hospital. Written informed consent was obtained from all subjects, the parents or legal guardians of any participant under the age of 16 .

\section{Consent for publication}

Not applicable.

\section{Competing interests}

The authors declare that they have no competing interests.

\section{Author details}

'Department of Ophthalmology, Xi'an No.1 Hospital, Xi'an 710002, Shaanxi Province, China. ${ }^{2}$ Shaanxi Institute of Ophthalmology, Xi'an 710002, Shaanxi Province, China. '3 Shaanxi Key Laboratory of Ophthalmology, Xi'an 710002, Shaanxi Province, China. ${ }^{4}$ Clinical Research Center for Ophthalmology Diseases of Shaanxi Province, Xi'an 710002, Shaanxi Province, China. ${ }^{5}$ First Affiliated Hospital of Northwestern University, Xi'an 710002, Shaanxi Province, China.

Received: 23 February 2020 Accepted: 25 August 2020

Published online: 31 August 2020

\section{References}

1. Looker KJ, Magaret AS, May MT, et al. Global and regional estimates of prevalent and incident herpes simplex virus type 1 infections in 2012. PLoS One. 2015;10(10):e0140765. https://doi.org/10.1371/journal.pone.0140765.

2. Rowe AM, St Leger AJ, Jeon S, et al. Herpes keratitis. Prog Retin Eye Res. 2013;32:88-101. https://doi.org/10.1016/j.preteyeres.2012.08.002.

3. Koujah L, Suryawanshi RK, Shukla D. Pathological processes activated by herpes simplex virus-1 (HSV-1) infection in the cornea. Cell Mol Life Sci. 2019;76(3):405-19. https://doi.org/10.1007/s00018-018-2938-1.

4. Royer DJ, Cohen A, Carr D. The current state of vaccine development for ocular HSV-1 infection. Expert Rev Ophthalmol. 2015;10(2):113-26. https:// doi.org/10.1586/17469899.2015.1004315.

5. Stanfield B, Kousoulas KG. Herpes simplex vaccines: prospects of liveattenuated HSV vaccines to combat genital and ocular infections. Curr Clin Microbiol Rep. 2015;2(3):125-36. https://doi.org/10.1007/s40588-015-0020-4.

6. Ding $X$, Sanchez DJ, Shahangian A, et al. Cascade search for HSV-1 combinatorial drugs with high antiviral efficacy and low toxicity. Int J Nanomedicine. 2012;7:2281-92. https://doi.org/10.2147/IJN.S27540.

7. Andrei G, Snoeck R. Herpes simplex virus drug-resistance: new mutations and insights. Curr Opin Infect Dis. 2013;26(6):551-60. https://doi.org/10. 1097/QCO.0000000000000015.

8. von Thun Und Hohenstein-Blaul N, Funke S, Grus FH. Tears as a source of biomarkers for ocular and systemic diseases. Exp Eye Res. 2013;117:126-37. https://doi.org/10.1016/j.exer.2013.07.015. 
9. Azkargorta M, Soria J, Acera A, et al. Human tear proteomics and peptidomics in ophthalmology: toward the translation of proteomic biomarkers into clinical practice. J Proteome. 2017;150:359-67. https://doi. org/10.1016/j.jprot.2016.05.006.

10. Jung JH, Ji YW, Hwang HS, et al. Proteomic analysis of human lacrimal and tear fluid in dry eye disease. Sci Rep. 2017;7(1):13363. Published 2017 Oct 17. https://doi.org/10.1038/s41598-017-13817-y.

11. Huang Z, Du CX, Pan XD. The use of in-strip digestion for fast proteomic analysis on tear fluid from dry eye patients. PLoS One. 2018;13(8):e0200702. https://doi.org/10.1371/journal.pone.0200702.

12. Bouhenni $R$, Dunmire J, Rowe $T$, et al. Proteomics in the study of bacterial keratitis. Proteomes. 2015;3(4):496-511. https://doi.org/10.3390/ proteomes3040496.

13. Ananthi S, Venkatesh Prajna N, Lalitha $P$, et al. Pathogen induced changes in the protein profile of human tears from Fusarium keratitis patients. PLoS One. 2013;8(1):e53018. https://doi.org/10.1371/journal.pone.0053018.

14. Kandhavelu J, Demonte NL, Namperumalsamy VP, et al. Aspergillus flavus induced alterations in tear protein profile reveal pathogen-induced host response to fungal infection. J Proteome. 2017;152:13-21. https://doi.org/10. 1016/j.jprot.2016.10.009.

15. Kim HJ, Kim PK, Yoo HS, et al. Comparison of tear proteins between healthy and early diabetic retinopathy patients. Clin Biochem. 2012;45(1-2):60-7. https://doi.org/10.1016/j.clinbiochem.2011.10.006.

16. Csősz É, Boross P, Csutak A, et al. Quantitative analysis of proteins in the tear fluid of patients with diabetic retinopathy. J Proteome. 2012;75(7):2196204. https://doi.org/10.1016/j.jprot.2012.01.019.

17. Kishazi E, Dor M, Eperon S, et al. Thyroid-associated orbitopathy and tears: a proteomics study. J Proteome. 2018;170:110-6. https://doi.org/10.1016/j. jprot.2017.09.001.

18. Lebrecht A, Boehm D, Schmidt M, et al. Diagnosis of breast cancer by tear proteomic pattern. Cancer Genomics Proteomics 2009;6(3):177-182.

19. Böhm D, Keller K, Pieter J, et al. Comparison of tear protein levels in breast cancer patients and healthy controls using a de novo proteomic approach. Oncol Rep. 2012;28(2):429-38. https://doi.org/10.3892/or.2012.1849.

20. Hagan S, Martin E, Enríquez-de-Salamanca A. Tear fluid biomarkers in ocular and systemic disease: potential use for predictive, preventive and personalised medicine. EPMA J. 2016;7(1):15. Published 2016 Jul 13. https:// doi.org/10.1186/s13167-016-0065-3.

21. Burrows J, Nitsche A, Bayly B, et al. Detection and subtyping of Herpes simplex virus in clinical samples by LightCycler PCR, enzyme immunoassay and cell culture. BMC Microbiol. 2002;2:12. Published 2002 Jun 9. https://doi. org/10.1186/1471-2180-2-12.

22. Dor M, Eperon S, Lalive $\mathrm{PH}$, et al. Investigation of the global protein content from healthy human tears. Exp Eye Res. 2019;179:64-74. https://doi.org/10. 1016/j.exer.2018.10.006

23. Cui YH, Liu Q, Xu ZY, et al. Quantitative proteomic analysis of human corneal epithelial cells infected with HSV-1. Exp Eye Res. 2019;185:107664. https://doi.org/10.1016/j.exer.2019.05.004.

24. Benayas B, Sastre I, López-Martín S, et al. Tetraspanin CD81 regulates HSV-1 infection [published online ahead of print, 2020 Jun 4]. Med Microbio Immunol. 2020:1-10. https://doi.org/10.1007/s00430-020-00684-0.

25. Walsh D, Mohr I. Phosphorylation of elF4E by Mnk-1 enhances HSV-1 translation and replication in quiescent cells. Genes Dev. 2004;18(6):660-72. https://doi.org/10.1101/gad.1185304.

26. Miles DH, Willcox MD, Athmanathan S. Ocular and neuronal cell apoptosis during HSV-1 infection: a review. Curr Eye Res. 2004;29(2-3):79-90. https:// doi.org/10.1080/02713680490504669.

27. Shahiduzzaman M, Coombs KM. Activity based protein profiling to detect serine hydrolase alterations in virus infected cells. Front Microbiol. 2012;3: 308. https://doi.org/10.3389/fmicb.2012.00308.

28. Mathys L, Balzarini J. The role of cellular oxidoreductases in viral entry and virus infection-associated oxidative stress: potential therapeutic applications. Expert Opin Ther Targets. 2016;20(1):123-43. https://doi.org/10.1517/ 14728222.2015 .1068760 .

29. Bryant-Hudson KM, Gurung HR, Zheng $M$, et al. Tumor necrosis factor alpha and interleukin-6 facilitate corneal lymphangiogenesis in response to herpes simplex virus 1 infection. J Virol. 2014;88(24):14451-7. https://doi.org/10. 1128/JVI.01841-14

30. Voss A, Gescher K, Hensel A, et al. Double-stranded RNA induces $\$ 100$ gene expression by a cycloheximide-sensitive factor. FEBS Lett. 2012;586(2):196203. https://doi.org/10.1016/j.febslet.2011.12.022.
31. Wuest TR, Carr DJ. VEGF-A expression by HSV-1-infected cells drives corneal lymphangiogenesis. J Exp Med. 2010;207(1):101-15. https://doi.org/10.1084/ jem.20091385

32. Araki-Sasaki $K$, Tanaka $T$, Ebisuno $Y$, et al. Dynamic expression of chemokines and the infiltration of inflammatory cells in the HSV-infected cornea and its associated tissues. Ocul Immunol Inflamm. 2006;14(5):257-66. https://doi. org/10.1080/09273940600943581.

33. Zhou L, Zhao SZ, Koh SK, et al. In-depth analysis of the human tear proteome. J Proteome. 2012;75(13):3877-85. https://doi.org/10.1016/j.jprot. 2012.04.053.

34. Green LK, Pavan-Langston D. Herpes simplex ocular inflammatory disease. Int Ophthalmol Clin. 2006;46(2):27-37. https://doi.org/10.1097/00004397200604620-00005

35. Guo H, Pang K, Wei Y, et al. Herpes virus entry mediator in human corneal epithelial cells modulates the production of inflammatory cytokines in response to HSV type 1 challenge. Ophthalmic Res. 2015;54(3):128-34 https://doi.org/10.1159/000437209.

36. Heiligenhaus A, Bauer D, Zheng M, et al. CD4+ T-cell type 1 and type 2 cytokines in the HSV-1 infected cornea. Graefes Arch Clin Exp Ophthalmol. 1999;237(5):399-406. https://doi.org/10.1007/s004170050251.

37. Milora KA, Miller SL, Sanmiguel JC, et al. Interleukin-1a released from HSV-1infected keratinocytes acts as a functional alarmin in the skin. Nat Commun. 2014;5:5230. https://doi.org/10.1038/ncomms6230.

38. Netea MG, van de Veerdonk FL, van der Meer JW, et al. Inflammasomeindependent regulation of IL-1-family cytokines. Annu Rev Immunol. 2015; 33:49-77. https://doi.org/10.1146/annurev-immunol-032414-112306.

39. Teng MW, Bowman EP, McElwee JJ, et al. IL-12 and IL-23 cytokines: from discovery to targeted therapies for immune-mediated inflammatory diseases. Nat Med. 2015;21(7):719-29. https://doi.org/10.1038/nm.3895.

40. Schröder JM, Harder J. Human beta-defensin-2. Int J Biochem Cell Biol. 1999; 31(6):645-51. https://doi.org/10.1016/s1357-2725(99)00013-8.

41. McDermott AM, Redfern RL, Zhang B, et al. Defensin expression by the cornea: multiple signalling pathways mediate IL-1beta stimulation of hBD-2 expression by human corneal epithelial cells. Invest Ophthalmol Vis Sci. 2003:44(5):1859-65. https://doi.org/10.1167/iovs.02-0787.

42. Bucki R, Leszczyńska K, Namiot A, Sokołowski W, et al. Cathelicidin LL-37: a multitask antimicrobial peptide. Arch Immunol Ther Exp. 2010;58(1):15-25. https://doi.org/10.1007/s00005-009-0057-2.

43. Lee CJ, Buznyk O, Kuffova L, et al. Cathelicidin LL-37 and HSV-1 corneal infection: peptide versus gene therapy. Transl Vis Sci Technol. 2014;3(3):4. https://doi.org/10.1167/tvst.3.3.4.

44. Verjans ET, Zels S, Luyten W, et al. Molecular mechanisms of LL-37-induced receptor activation: an overview. Peptides. 2016;85:16-26. https://doi.org/10. 1016/j.peptides.2016.09.002.

\section{Publisher's Note}

Springer Nature remains neutral with regard to jurisdictional claims in published maps and institutional affiliations.

Ready to submit your research? Choose BMC and benefit from:

- fast, convenient online submission

- thorough peer review by experienced researchers in your field

- rapid publication on acceptance

- support for research data, including large and complex data types

- gold Open Access which fosters wider collaboration and increased citations

- maximum visibility for your research: over $100 \mathrm{M}$ website views per year

At BMC, research is always in progress.

Learn more biomedcentral.com/submissions 